\title{
Variations in Infant CYP2B6 Genotype Associated with the Need for Pharmacological Treatment for Neonatal Abstinence Syndrome in Infants of Methadone-Maintained Opioid-Dependent Mothers
}

\author{
Helen Mactier, MBChB, MD ${ }^{1}$ Poppy McLaughlin, $\mathrm{PhD}^{2}$ Cheryl Gillis, MBChB \\ Michael David Osselton, PhD $^{2}$
} 1 Neonatal Unit, Princess Royal Maternity, Glasgow, United Kingdom
2 Department of Anthropology and Forensic Science, Bournemouth
University, Fern Barrow, Poole, United Kingdom
Address for correspondence Helen Mactier, MBChB, MD, Neonatal Unit, Princess Royal Maternity, 8-16 Alexandra Parade, Glasgow G31 2ER, United Kingdom (e-mail: Helen.mactier@ggc.scot.nhs.uk).

Am J Perinatol 2017;34:918-921.

\begin{abstract}
Background Neonatal abstinence syndrome (NAS) in infants of methadone-maintained opioid-dependent (MMOD) mothers cannot be predicted in individual cases. We investigated whether variation in infant genotype is associated with severity of NAS. Methods This is a pilot observational cohort study of 21 MMOD mothers and their newborns. Infant buccal swabs were obtained soon after delivery, together with a maternal blood sample for the determination of maternal plasma methadone concentration. Genomic variation in five opioid-related genes (ABCB1, COMT, CYP2B6, CYP2D6, and OPRM1) was ascertained from infant buccal swabs and related to need for pharmacological treatment of NAS.

Results Out of 21 infants, 11 (52\%) required treatment for NAS. Mothers of treated infants tended to have been prescribed higher doses of methadone, but plasma metha-

\section{Keywords}

- neonatal abstinence syndrome

- newborn

- methadone

- genotype done concentrations did not differ between mothers of treated or untreated babies. Treated and untreated babies did not differ in terms of method of feeding. Treated infants were more likely to carry the normal (homozygous) allele at 516 and 785 regions of CYP2B6 gene ( $p=0.015$ and 0.023 , respectively). There were no differences in any other genes between infants who did or did not require treatment for NAS.

Conclusion Genomic variation in CYP2B6 may explain, at least in part, severity of NAS.
\end{abstract}

Neonatal abstinence syndrome (NAS) is a common complication of opioid dependency in pregnancy, particularly when the latter is managed with maintenance methadone. The likelihood of the infant developing NAS is greater for polydrug-misusing women and is reduced by breastfeeding. ${ }^{1,2}$ There is conflicting evidence with regard to whether severity of NAS is related to the maternal dose of methadone. ${ }^{2,3}$ Differences in pharmacokinetics and pharmacogenetics are likely to influence the baby's postnatal response to in utero drug exposure. ${ }^{4}$

received

October 23, 2016

accepted after revision

February 9, 2017

published online

March 20, 2017
Variation in opioid metabolism is well recognized in adults. The CYP2B6 gene encodes a cytochrome P450 mono-oxygenase enzyme involved in the metabolism of methadone. Seventy-five percent of the Caucasian population carries the homozygous, or wild-type, alleles at CYP2B6 $516 \mathrm{G}>\mathrm{T}$ and $785 \mathrm{~A}>\mathrm{G}$, associated with normal enzyme function. $^{5}$ Single-nucleotide polymorphisms (SNPs) in $C Y P 2 B 6$ are associated with variation in methadone response and carriers of the CYP2B $6^{*} 6$ genotype demonstrate slower metabolism and higher trough plasma concentrations of

Copyright @ 2017 by Thieme Medical Publishers, Inc., 333 Seventh Avenue, New York, NY 10001, USA Tel: +1(212) 584-4662.
DOI https://doi.org/ 10.1055/s-0037-1600917. ISSN 0735-1631. 
methadone compared with noncarriers. ${ }^{6-8}$ SNPs in OPRM1 and COMT opioid-related genes in the infant are associated with NAS treatment and length of hospital stay, ${ }^{9}$ but to date the association between SNPs in infant CYP2B6 and NAS has not been reported.

\section{Methods}

All methadone-maintained opioid-dependent (MMOD) mothers delivering after 36 weeks' gestation in a single maternity unit in Glasgow were eligible to participate in this study if they were being accommodated with their baby in the postnatal ward. Potential participants were identified in the postnatal wards within 48 hours of delivery. Mothers had been managed within a multidisciplinary service for women with substance misuse problems; methadone maintenance was provided in collaboration with social work and addiction services, tailored to symptoms. Sufficient methadone was prescribed to eliminate physical withdrawals, with the aim of reducing to the lowest acceptable dose of methadone prior to delivery.

Following parental consent, a buccal swab (Catch-All; Cambio Ltd., Cambridge) was obtained from the baby and a venous blood sample obtained from the mother for estimation of trough plasma methadone concentration.

Demographic data included maternal age and prescribed dose of methadone at delivery, infant gestation, birth weight, feeding method, and duration of hospital stay. Local policy was to nurse all babies of MMOD mothers in the postnatal ward with their mothers, regardless of the need for NAS treatment unless the baby had another medical or social indication for admission to the neonatal unit. NAS was managed according to protocol using a local version of the Lipsitz system for scoring. ${ }^{10}$ Infants who scored 5 or more on two consecutive occasions and/or with poor feeding or ongoing weight loss after 5 days were commenced on oral morphine at $60 \mu \mathrm{g} / \mathrm{kg}$ six times daily. Dose was increased to $80 \mu \mathrm{g} / \mathrm{kg}$ per dose if the baby remained symptomatic; otherwise morphine was weaned daily by $10 \mu \mathrm{g} / \mathrm{kg} / \mathrm{dose}$. If NAS symptoms were not controlled by oral morphine, phenobarbital was given in addition. Regardless of treatment, all infants remained in the postnatal ward with their mother for a minimum of 5 days. Length of stay for treated babies was determined by success of weaning of morphine; for treatment periods longer than 10 to 12 days, the mother was discharged from hospital and baby admitted to the neonatal unit. Following weaning of oral morphine, phenobarbital treatment could be continued as an outpatient. Breastfeeding was encouraged for all babies. The research team was not involved in any decision to treat an infant.

Buccal DNA was extracted from swabs by immersion in QuickExtract DNA solution (Cambio Ltd., Cambridge). Extracted DNA was analyzed for genomic variants in five genes; ABCB1, COMT, CYP2B6, CYP2D6, and OPRM1 by LGC Genomics using Kompetitive Allele Specific Polymerase chain reaction (KASP). SNPs analyzed included ABCB1 $1236 \mathrm{C}>\mathrm{T}$, $2677 \mathrm{G}>\mathrm{T}$, and $3435 \mathrm{C}>\mathrm{T}$; COMT $-98 \mathrm{~A}>\mathrm{G}, 186 \mathrm{C}>\mathrm{T}, 408 \mathrm{C}>\mathrm{G}$, and $472 \mathrm{~A}>\mathrm{G}$; CYP2B6 $516 \mathrm{G}>\mathrm{T}$ and $785 \mathrm{~A}>\mathrm{G}$; CYP2D6 1707
T>delT; and OPRM1 118 A>G. The number of functioning CYP2D6 alleles was ascertained using a Hy-Beacon assay (LGC Genomics, Teddington). Maternal plasma samples were analyzed for methadone using liquid-liquid extraction and subsequent gas chromatography mass spectrometry.

The influence of gestation, birth weight, methadone dose, and plasma methadone concentration on NAS treatment and length of hospital stay was determined using independent sample $t$-tests (parametric) or Mann-Whitney $U$-test (nonparametric data). Fisher's exact test was used to compare genotype distribution between infants who did or did not require treatment for NAS. The study was approved by West of Scotland Research Ethics Committee, and written informed consent obtained from all participating mothers.

\section{Results}

Twenty-one of 22 mothers approached agreed to participate; samples were obtained from all 21 mother-infant pairs. Gestation ranged from $36^{+1}$ to $41^{+0}$ (median $39^{+0}$ ) weeks and birth weight from 2,198 to 3,400 (median: 2,746) g. Median maternal age at delivery was 32 (range: 25-42) years. Median prescribed dose of methadone at delivery was 55 (range: 2-100) mg; all mothers reported cigarette smoking. Maternal plasma methadone concentration ranged from 20 to 720 (median: 200) ng/mL.

Eleven of 21 (52\%) infants required treatment with oral morphine, five of whom additionally received phenobarbital. Total duration of treatment varied from 8 to 134 (median: 44 ) days. There was no difference between babies who did or did not receive treatment in terms of gestation, birth weight, or method of feeding. Treated babies' length of hospital stay was longer (median: 20 [range: 10-42] vs. 7 [range: 5 - 11] days; $p<0.005)$. Mothers of treated infants were older $(p=0.02)$ and tended to be prescribed higher doses of methadone; plasma concentrations of methadone tended to be higher for mothers of treated infants, but the difference was not significant ( - Table 1). All mothers and their partners were of Caucasian origin.

Methadone-exposed infants who required treatment for NAS were more likely to carry the normal (homozygous) allele at 516 ( $n=8$ [treated] vs. 1 [untreated]: $p=0.015$ ) and $785(n=7$ [treated] vs. 2 [untreated]: $p=0.023$ ) regions of the CYP2B6 gene (-Table 2 ). There were no differences between treated and untreated babies in any other genes studied.

\section{Discussion}

NAS is a common condition which accounts for a significant and increasing proportion of neonatal care worldwide. ${ }^{11}$ NAS is poorly predicted, resulting in many babies and their mothers having a prolonged postnatal stay for observation of developing NAS. Being able to predict NAS would reduce unnecessary hospital stay and its associated costs, and also afford an opportunity to investigate preemptive treatment for babies likely to develop NAS. 
Table 1 Demographic and genomic data for methadone-exposed babies according to treatment of neonatal abstinence syndrome (NAS)

\begin{tabular}{|c|c|c|c|}
\hline Variables & $\begin{array}{l}\text { Infants requiring NAS } \\
\text { treatment }(n=11)\end{array}$ & $\begin{array}{l}\text { Infants not requiring NAS } \\
\text { treatment }(n=10)\end{array}$ & $p$-Value \\
\hline Gestation (wk) (median [range]) & $39^{+1}\left(36^{+5}-41^{+0}\right)$ & $38^{+4}\left(36^{+1}-40^{+4}\right)$ & 0.408 \\
\hline Birth weight (g) (median [range]) & $2,731(2,300-3,240)$ & $2,876(2,198-3,400)$ & 0.378 \\
\hline Length of hospital stay (d) (median [range]) & $19(10-42)$ & $7(5-11)$ & 0.004 \\
\hline Maternal age (y) (median [range]) & $34(28-42)$ & $30(25-37)$ & 0.021 \\
\hline Maternal methadone dose $(\mathrm{mg})$ (median [range]) & $65(30-100)$ & $54(2-100)$ & 0.391 \\
\hline $\begin{array}{l}\text { Maternal plasma methadone concentration }(\mu \mathrm{g} / \mathrm{L}) \\
\text { (median [range]) }\end{array}$ & $320(80-660)$ & $165(20-720)$ & 0.315 \\
\hline
\end{tabular}

The CYP2B6* 6 genotype is commonly reported in Caucasian populations and is associated with slower metabolism of methadone. ${ }^{7}$ Within our infant population, the overall frequency of the CYP2B6* 6 genotype was $25 \%$, consistent with the general Caucasian population, but untreated infants were much more likely to carry alleles associated with decreased enzyme function at CYP2B6 $516 \mathrm{G}>\mathrm{T}$ and 785 $A>G$. Doberczak et al ${ }^{12}$ reported more than 20 years ago that severity of NAS was related to the rate of decline of the

Table 2 Relative frequency of different genotypes for treated $(n=11)$ and untreated $(n=10)$ infants

\begin{tabular}{|c|c|c|c|c|c|}
\hline \multicolumn{3}{|l|}{ Gene } & \multirow{2}{*}{$\begin{array}{l}\begin{array}{l}\text { Treated } \\
(n)\end{array} \\
7 \\
\end{array}$} & \multirow{2}{*}{$\begin{array}{l}\text { Untreated } \\
(n)\end{array}$} & \multirow{2}{*}{$\begin{array}{l}p \text {-Value } \\
1.0\end{array}$} \\
\hline \multirow[t]{6}{*}{$A B C B 1$} & \multirow[t]{2}{*}{1236} & $\mathrm{CC} / \mathrm{CT}$ & & & \\
\hline & & TT & 2 & 3 & \\
\hline & \multirow[t]{2}{*}{2677} & GG/GT & 8 & 7 & \multirow[t]{2}{*}{1.0} \\
\hline & & $\mathrm{TT}$ & 2 & 3 & \\
\hline & \multirow{2}{*}{3435} & $\mathrm{CC} / \mathrm{CT}$ & 5 & 7 & \multirow[t]{2}{*}{0.65} \\
\hline & & $\mathrm{TT}$ & 4 & 3 & \\
\hline \multirow[t]{8}{*}{ COMT } & \multirow[t]{2}{*}{186} & $\mathrm{CC} / \mathrm{CT}$ & 6 & 6 & \multirow[t]{2}{*}{0.638} \\
\hline & & $\mathrm{TT}$ & 4 & 2 & \\
\hline & \multirow[t]{2}{*}{472} & $\mathrm{AA}$ & 4 & 6 & \multirow[t]{2}{*}{0.303} \\
\hline & & GG/GA & 1 & 9 & \\
\hline & \multirow[t]{2}{*}{408} & CG/GG & 4 & 7 & \multirow[t]{2}{*}{0.63} \\
\hline & & $\mathrm{CC}$ & 4 & 3 & \\
\hline & \multirow[t]{2}{*}{-98} & $\mathrm{AA}$ & 4 & 4 & \multirow[t]{2}{*}{1.0} \\
\hline & & GG/GA & 6 & 6 & \\
\hline \multirow[t]{4}{*}{ CYP2D6 } & \multirow{2}{*}{1707} & TT & 9 & 10 & \multirow[t]{2}{*}{1.0} \\
\hline & & delT & 1 & 0 & \\
\hline & \multirow{2}{*}{$\begin{array}{l}\text { Number of } \\
\text { functioning } \\
\text { alleles }\end{array}$} & 1 & 0 & 2 & \multirow[t]{2}{*}{0.474} \\
\hline & & 2 & 10 & 8 & \\
\hline \multirow[t]{2}{*}{ OPRM1 } & \multirow[t]{2}{*}{118} & AA & 8 & 9 & \multirow[t]{2}{*}{1.0} \\
\hline & & GG/GA & 1 & 1 & \\
\hline \multirow[t]{4}{*}{ CYP2B6 } & \multirow[t]{2}{*}{516} & GG & 8 & 1 & \multirow[t]{2}{*}{0.015} \\
\hline & & GT & 2 & 7 & \\
\hline & \multirow[t]{2}{*}{785} & $\mathrm{AA}$ & 7 & 2 & \multirow[t]{2}{*}{0.023} \\
\hline & & AG & 2 & 8 & \\
\hline
\end{tabular}

infant's plasma methadone concentration over the first 4 days of life. Our findings are consistent with these findings, with slower metabolism of methadone in the infant less likely to result in abrupt withdrawal from transplacentally acquired methadone and hence less severe NAS. Mothers of treated babies tended to have been on higher doses of methadone at delivery, but their plasma concentrations of methadone were not significantly higher, suggesting faster maternal metabolism of methadone, consistent with their infants. A genomic variant of CYP2B6 common to mother and baby would explain both larger dosages of methadone required by the mother to control cravings for opioid and faster decline in neonatal plasma methadone concentration reflected in more severe neonatal withdrawal. Genetic variation may also explain, at least in part, why there is differing opinion as to whether maternal methadone dose is reflected in the likelihood of the baby developing NAS. ${ }^{2,3}$

The weaknesses of this study are the small number of patients, lack of toxicology to confirm additional substance misuse during pregnancy, and absence of maternal genetic data. Mean plasma methadone concentration was almost twice as high in mothers of treated babies, but the range of values was very similar for both groups; small study numbers may have contributed to a type II error. Additional substance misuse is notoriously difficult to ascertain from maternal history, but within the population attending our service polydrug use is common and positively correlated with the prescribed dose of methadone. ${ }^{2}$ A previous study demonstrated ongoing illicit drug use in $90 \%$ of our MMOD mothers, predominantly benzodiazepines and heroin, ${ }^{13}$ and all of the mothers included in this study reported cigarette smoking. It is possible that both nicotine and additional substances of abuse contributed to the development of NAS.

$A B C B 1$ affects drug deposition rather than metabolism and SNPs in this gene are unrelated to opioid addiction in adults. ${ }^{7}$ Consistent with published literature, we did not see differences in $A B C B 1$ associated with the likelihood of the baby requiring treatment for NAS. ${ }^{9}$ Maternal CYP2D6 genotype has been associated with higher than predicted conversion of codeine to morphine and fatal respiratory depression in a breast-fed baby, but the latter genotype is uncommon in the Caucasian population. ${ }^{14}$ We did not see any association between NAS and either of the two CYP2D6 genotypes tested 
in this study. Small study numbers may explain our failure to replicate the findings of Wachman et al, in whose study SNPs in both OPRM1 and COMT predicted NAS. ${ }^{9}$

The strengths of this small pilot study are that mothers and babies were cared for in one facility, with a practiced and consistent approach to management of NAS. Persons caring for the babies were unaware of the infant's genotype. Even within a small number of patients, genomic variation in CYP2B6 between treated and untreated babies was significant.

Future studies should consider maternal genotype and its relationship to infant genotype and/or the prediction of NAS as well as associated maternal polydrug use.

\section{Conclusion}

Genomic variation in CYP2B6 in the newborn is associated with severity of NAS; this has not previously been reported. Better understanding of the role of pharmacogenetics in the etiology of NAS may result in improved care for mother and baby.

Note

This study was undertaken as part of a $\mathrm{PhD}$ cosponsored by Bournemouth University and Randox. Royal Bournemouth Hospital donated the space for sample analysis.

\section{Authors' Contributions}

Helen Mactier was involved in study concept and sample collection and wrote the manuscript. Poppy McLaughlin analyzed samples and data, contributed to manuscript revisions, and approved the final version. Cheryl Gillis recruited patients and collected samples, contributed to manuscript revisions, and approved the final version. Michael David Osselton conceived the study, oversaw analysis of samples, contributed to manuscript revisions, and approved the final version.

\section{Conflict of Interest}

None.

\section{References}

1 Abdel-Latif ME, Pinner J, Clews S, Cooke F, Lui K, Oei J. Effects of breast milk on the severity and outcome of neonatal abstinence syndrome among infants of drug-dependent mothers. Pediatrics 2006;117(6):e1163-e1169

2 Dryden C, Young D, Hepburn M, Mactier H. Maternal methadone use in pregnancy: factors associated with the development of neonatal abstinence syndrome and implications for healthcare resources. BJOG 2009;116(5):665-671

3 Cleary BJ, Donnelly JM, Strawbridge JD, et al. Methadone and perinatal outcomes: a retrospective cohort study. Am J Obstet Gynecol 2011;204(2):139.e1-139.e9

4 Lewis T, Dinh J, Leeder JS. Genetic determinants of fetal opiate exposure and risk of neonatal abstinence syndrome: knowledge deficits and prospects for future research. Clin Pharmacol Ther 2015;98(3):309-320

5 NCBI database of Short Genetic Variations (dbSNP). Available at: https://www.ncbi.nlm.nih.gov/snp; Accessed December 15, 2016

6 Bunten H, Liang WJ, Pounder DJ, Seneviratne C, Osselton D. OPRM1 and CYP2B6 gene variants as risk factors in methadonerelated deaths. Clin Pharmacol Ther 2010;88(3):383-389

7 Dennis BB, Bawor M, Thabane L, Sohani Z, Samaan Z. Impact of ABCB1 and CYP2B6 genetic polymorphisms on methadone metabolism, dose and treatment response in patients with opioid addiction: a systematic review and meta-analysis. PLoS One 2014;9(1): e86114. Doi: 10.1371/journal.pone.0086114

8 Gadel S, Crafford A, Regina K, Kharasch ED. Methadone N-demethylation by the common CYP2B6 allelic variant CYP2B6.6. Drug Metab Dispos 2013;41(4):709-713

9 Wachman EM, Hayes MJ, Brown MS, et al. Association of OPRM1 and COMT single-nucleotide polymorphisms with hospital length of stay and treatment of neonatal abstinence syndrome. JAMA 2013;309(17):1821-1827

10 Lipsitz PJ. A proposed narcotic withdrawal score for use with newborn infants. A pragmatic evaluation of its efficacy. Clin Pediatr (Phila) 1975;14(6):592-594

11 Tolia VN, Patrick SW, Bennett MM, et al. Increasing incidence of the neonatal abstinence syndrome in U.S. neonatal ICUs. N Engl J Med 2015;372(22):2118-2126

12 Doberczak TM, Kandall SR, Friedmann P. Relationships between maternal methadone dosage, maternal-neonatal methadone levels, and neonatal withdrawal. Obstet Gynecol 1993;83:936-940

13 McGlone L, Hamilton R, McCulloch DL, et al. Neonatal visual evoked potentials are altered in infants born to mothers prescribed methadone in pregnancy. Pediatrics 2013;131:e857-e863

14 Koren G, Cairns J, Chitayat D, Gaedigk A, Leeder SJ. Pharmacogenetics of morphine poisoning in a breastfed neonate of a codeineprescribed mother. Lancet 2006;368(9536):704. Doi: 10.1016/ S0140-6736(06)69255-6 